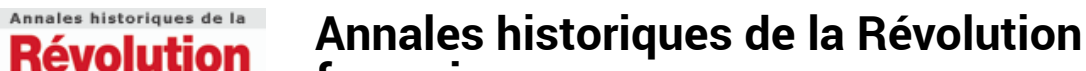

française française

344 | avril-juin 2006

La prise de parole publique des femmes

\section{5, la création de Don Juan à l'opéra de Paris}

\section{Gérard Loubinoux}

\section{(2) OpenEdition}

\section{Journals}

Édition électronique

URL : https://journals.openedition.org/ahrf/6732

DOI : $10.4000 /$ ahrf.6732

ISSN : 1952-403X

\section{Éditeur :}

Armand Colin, Société des études robespierristes

\section{Édition imprimée}

Date de publication : 1 juin 2006

Pagination : 266-267

ISSN : 0003-4436

\section{Référence électronique}

Gérard Loubinoux, « 1805, la création de Don Juan à l'opéra de Paris ». Annales historiques de la Révolution française [En ligne], 344 | avril-juin 2006, mis en ligne le 02 juillet 2008, consulté le 23 avril 2022. URL : http://journals.openedition.org/ahrf/6732 ; DOI : https://doi.org/10.4000/ahrf.6732

Ce document a été généré automatiquement le 23 avril 2022.

Tous droits réservés 


\title{
1805, la création de Don Juan à l'opéra de Paris
}

\author{
Gérard Loubinoux
}

\section{RÉFÉRENCE}

Laurent MARTY, 1805, la création de Don Juan à l'opéra de Paris, Paris, L'Harmattan, 2005, 290 p., ISBN 2-7475-9107-7, $26 €$.

1 Cet ouvrage traite de la première française du Don Giovanni de Mozart dans l'adaptation de H.-J. Thuring, général de brigade, et D. Baillot, sous-bibliothécaire de la Bibliothèque impériale de Versailles, pour les paroles, et de M. C. Kalkbrenner pour la musique.

2 Laurent Marty, après avoir rappelé le contexte historique et musical, reconstitue les péripéties qui présidèrent à cette création: difficultés administratives ordinaires, rivalités diverses, problèmes technico-financiers, caprices des interprètes, etc. Il s'appuie en particulier sur la correspondance de Thuring, Bonet, directeur du Théâtre Impérial et Lucay, préfet du Palais. L'opiniâtreté de Thuring à faire représenter ce Don Juan y apparaît dans toute son âpreté face à la multiplication des obstacles. Il ressort en particulier une grande difficulté à réunir une distribution de qualité devant les défections en chaîne des chanteurs les plus en vue.

3 Suit une analyse méticuleuse du livret puis de la partition. La confrontation avec les originaux est conduite de façon systématique et pointilleuse. Il apparaît que les adaptateurs ont procédé à des modifications substantielles à tous niveaux. Leur manque de finesse est si éclatant que le détail de leur travail n'apporte pas même l'intérêt des adaptations de leurs prédécesseurs, contemporains ou successeurs de talent (Baurans, Calhava de l'Estandoux, Framery, Castil-Blaze). La bêtise patente et le manque de métier qui éclatent à chaque exemple rendent un peu vaine toute tentative d'interprétation, fût-elle transculturelle. Laurent Marty y voit tout de même une volonté délibérée d'édulcoration et d'affadissement non dépourvue d'arrière-pensées morales sinon politiques. 
4 De l'étude de l'accueil critique, très négativement escompté, on retiendra l'article du Moniteur, reproduit dans son intégralité, et qui présente une analyse très lucide des faiblesse de cette adaptation. Il n'y a pas lieu de s'étonner que le principe même de l'adaptation n'y soit pas remis en cause. La notion de fidélité à l'original est très largement postérieure et toute indignation à ce propos est anachronique et déplacée. Paradoxalement, c'est sur cette même notion de fidélité que se fondent les auteurs de l'adaptation dans leurs « observations préliminaires » au livret, reproduit intégralement à la fin de cette étude. Cela pourrait en faire des précurseurs si le respect revendiqué de l'original n'y était en fait qu'une excuse maladroite à la médiocrité de leur poésie et à l'absence flagrante de technique en matière d'adaptation. Cette revendication du respect de l'original est démentie par celle d'un impératif de bon goût propre à l'héritage culturel français face à la rusticité germanique et à la frivolité italienne.

Que la première apparition en France de Don Giovanni /Don Juan ait été un rapide fiasco en dépit du crédit de curiosité dont il bénéficiait n'a rien pour surprendre tant l'incapacité professionnelle des adaptateurs est rédhibitoire.

6 Cette chronique d'un échec annoncé trouve sans doute son intérêt majeur dans le suivi de l'étrange et pathétique prurit artistique qui travaille Thuring, "général et littérateur amateur ", s'accrochant obstinément à l'œuvre de Mozart dont il subodore miraculeusement le talent. 